\title{
Performance in classical eyelid conditioning as a function of the lengthening of the CS-UCS interval'
}

M. J. HOMZIE

UNIVERSITY OF DENVER

After receiving 49 eyelid conditioning trials with an ISI of $500 \mathrm{msec}$., human Ss were shifted to intervals of 600,800 , 1000,1500 , and $2500 \mathrm{msec}$. It was found that percentage of CRs of a latency appropriate to the original interval decreased during the post-shift trials for all groups with the exception of Group 600. Conditioning of the CRs appropriate to the new ISI was a negative function of the extent to which the interval was lengthened. Contrary to previous findings, these latter CRs did not develop gradually.

Boneau and his associates (Boneau, King, \& Kimble, 1956; Boneau, 1958) have studied the effects of a shift in the CS-UCS interval in classical eyelid conditioning. These investigators reported the occurrence of two apparently independent processes: CRs of a latency appropriate to the first conditioning interval gradually extinguished, while CRs of a latency appropriate to the new interval gradually increased. The present experiment is an attempt to study further the effects of elongating the interstimulus interval (ISI) in classical eyelid conditioning.

\section{Method}

The Ss were 87 students; the records of 27 of these Ss were eliminated for the following reasons: failure to reach the acquisition criterion of at least five CRs in the last 20 trials of acquisition $(N=6)$; CRs to test presentations of the CS alone $(\mathrm{N}=5)$; apparatus failure $(\mathrm{N}=3)$; classification as voluntary-form responders $(N=13)$. The remaining 60 Ss were randomly assigned to the three experimental groups.
The apparatus was the same as used in previous studies from the Iowa laboratory (cf., Spence, Homzie, \& Rutledge, 1964). The CS, a $70 \mathrm{~dB} 500 \mathrm{cps}$ tone, had a duration of $2550 \mathrm{msec}$. The UCS was a $1.0 \mathrm{psi}$ air puff of $50 \mathrm{msec}$. duration. The intertrial interval on any particular trial was 9,12 , or 15 sec., resulting in an average interval of $12 \mathrm{sec}$. A CR was recorded whenever the Brush recording pen showed a deflection of $1 \mathrm{~mm}$ or more in the range 150-500 $\mathrm{msec}$. following the onset of the CS. In order to study the acquisition of the conditioned eyelid response to the elongated CS-UCS intervals, CRs were also scored in the interval $350 \mathrm{msec}$. prior to the onset of the UCS.

The Ss were conditioned for 49 trials at a CS-UCS interval of $500 \mathrm{msec}$.; on the 50 th trial and for 30 subsequent trials, the interval was elongated to 600 msec., $800 \mathrm{msec}$, and $1000 \mathrm{msec}$. for Groups 600 , 800 , and 1000 , respectively. Other than the duration of the post-shift CS-UCS intervals, the procedures used in this experiment were identical to those employed by Spence, Homzie, \& Rutledge (1964). Therefore, it was possible to include some of the data from this latter study in the results of the present experiment; in particular, the data of the Ss initially conditioned at $500 \mathrm{msec}$. and then shifted to 1500 msec. (Group 1500, N = 25) and to $2500 \mathrm{msec}$. (Group 2500, $\mathrm{N}=25$ ).

\section{Results and Discussion}

Figure 1 shows the acquisition and post-shift performance of the five experimental groups. The groups

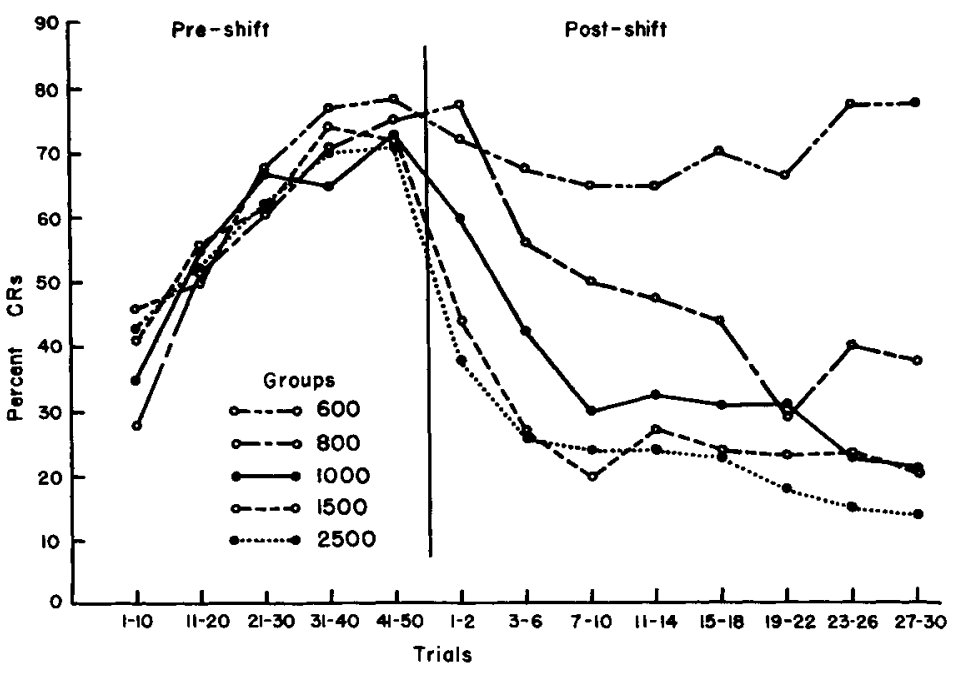

Fig. 1. Percentage of CRs occurring in the $150-500 \mathrm{msec}$. interval for all groups as a function of successive blocks of trials. 


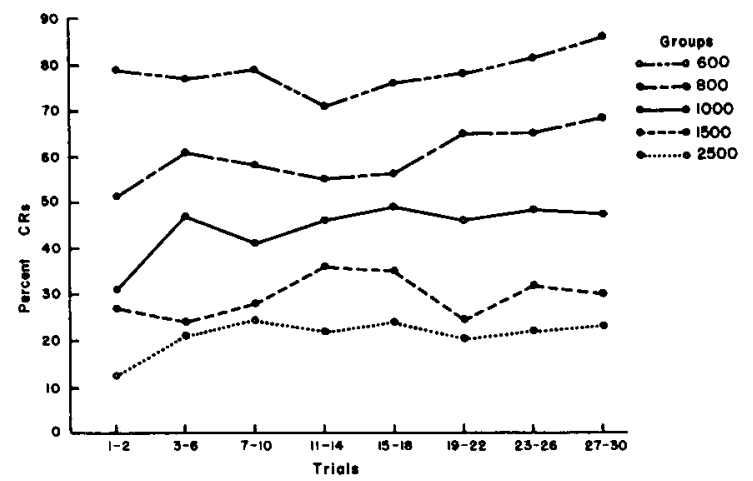

Fig. 2. Percentage of CRs occurring in the interval $350 \mathrm{msec}$. prior to the onset of the UCS for all groups as a function of successive blocks of post-shift trials.

appear to be comparable in pre-shift performance; an analysis of variance of the pre-shift performance of the groups resulted in an $F$ which was nonsignificant.

As Fig. 1 reveals, the percentage of CRs occurring in the interval $150-500 \mathrm{msec}$. following the onset of the CS decreased during the post-shift trials for all groups with the exception of Group 600. An analysis of variance of the number of CRs that each $\mathrm{S}$ made during the 30 post-shift trials resulted in an $F$ of $13.16(\mathrm{df}=4 / 105, \mathrm{p}<.01)$. Subsequent $\mathrm{t}$ tests indicated that Groups 1000,1500 , and 2500 were not significantly different from each other, and Group 800 was not significantly different from Group 1000. These results are in agreement with Boneau (1958) who reported no significant difference between a group shifted from .5 sec. to $1.0 \mathrm{sec}$. and a group shifted to $1.5 \mathrm{sec}$.

Figure 2 shows the post-shift performance of each group when CRs were scored the last $350 \mathrm{msec}$. prior to the onset of the UCS (e.g., Group 1000,650-1000

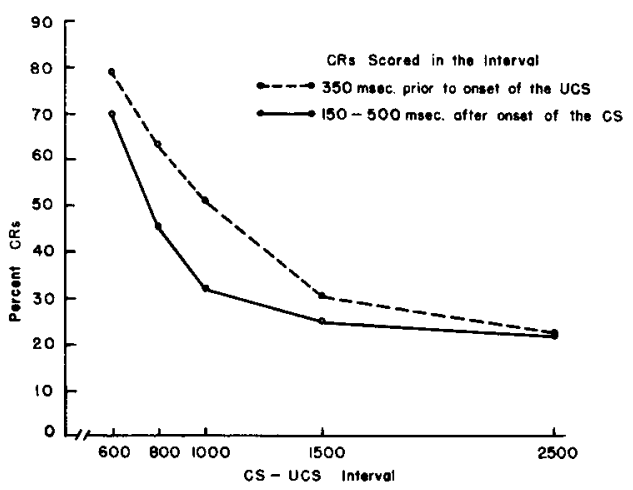

Fig. 3. Percentage of CRs occurring in the two CR scoring intervals during the post-shift trials as a function of the CS-UCS interval. msec.). The analysis of variance of the percentage of CRs each $\mathrm{S}$ made during the 30 post-shift trials resulted in a significant $F$ of 25.1 (df $=4 / 105, p<$ $.01)$. All $t$ test comparisons between the groups were statistically significant except for the comparison between Group 1500 and Group 2500. As may be seen in Fig. 2 the percentage of CRs of the five groups on the first two trials is in direct order of their nearness to the original conditioning interval. Contrary to Boneau's findings, the CRs of a latency appropriate to the new conditioning interval appear to have been established immediately with very little increase in their percentage of occurrence over the 30 post-shift trials. However, these findings are in agreement with a suggestion of Burstein (1965) that CRs acquired under a lengthened ISI are not independent of those conditioned at the original interval when the UCS intensity is weak.

Finally, turning to Fig. 3, which summarizes the post-shift results, the overall percentage of CRs during the 30 post-shift trials is plotted as a function of the CS-UCS interval. Two general conclusions seem to be suggested by these data. (1) In agreement with McAllister (1953) and Myers (1950) the dotted line curve indicates that conditioning is a negative function of the ISI at intervals beyond 500 msec. (2) The solid line in Fig. 3 reveals that there was an inverse monotonic relationship between the amount that the ISI was lengthened and the number of CRs the groups gave in the 150-500 msec. interval, indicating that extinction of CRs conditioned at a $.5 \mathrm{sec}$. ISI is a direct function of the extent to which the interval is elongated.

\section{References}

Boneau, C. A. The interstimulus interval and the latency of the conditioned eyelid response. J. exp. Psychol., 1958, 56, 464471.

Boneau, C. A., King, R. A., \& Kimble, G. A. The effect of changing the interstimulus interval on the acquisition of the conditioned eyelid response. Amer. Psychol., 1956, 11, 393.

Burstein, K. R. Effect of UCS intensity upon the acquisition of conditioned responses acquired under a lengthened interstimulus interval. J. exp. Psychol., 1965, 70, 147-150.

McAllister, W. R. Eyelid conditioning as a function of the CS-UCS interval. J. exp. Psychol., 1953, 45, 417-422.

Myers, J. An experimental investigation of the effects of varying the time between the onsets of the conditioned and unconditioned stimuli on the conditionod eyelid response. Unpublished Ph.D. dissertation, State University of Iowa, 1950.

Spence, K. W., Homzie, M., \& Rutledge, E. Extinction of the human eyelid $\mathrm{CR}$ as a function of the discriminability of the change from acquisition to extinction. J. exp. Psychol., 1964, 67, 545552.

\section{Note}

1. This report is based on a M.A. thesis submitted Aug. 1963 to the faculty at the University of Iowa. The study was directed by the late Prof. K. W. Spence as part of a project under Contract Nonr-1509(04). 